\title{
Lithium carbonate induced Histological changes in the Liver of Albino Rats
}

\author{
Gh. Mohd. Bhat ${ }^{1}$, Nasseer Ahmad Shah ${ }^{2}$, Bashir Ahamad Shah ${ }^{3}$, Shaheen \\ Shadad $^{4}$, Mohamad Saleem Itoo ${ }^{3}$, M. Aurif Maqdoomi ${ }^{5}$ \\ Department of Anatomy, Government Medical College Srinagar, J \& K, India. \\ 1Associate professor 2 Lecturer 3Assistant professor 4professsor 5Demonstrator
}

\begin{abstract}
Lithium is an integral drug used in the management of acute mania, unipolar and bipolar depression and prophylaxis of bipolar disorders. The aim of present study was to observe histological changes in the liver of lithium carbonate treated Albino rats. Sixty albino rats were taken and divided into two groups, group A (control group) of 15 animals, were fed with normal diet and group B of 45 animals, were fed normal diet along with lithium carbonate at the dose of 30mgs/ $/ \mathrm{kgm}$ body weight daily. The animals were sacrificed at four, eight and twelve week's interval, liver excised, $5 \mu \mathrm{m}$ thick sections prepared and stained with Haematoxylin and Eosin stain. On microscopic examination, as drug treatment continued the capsule remained intact, there was hepatic degeneration, followed by necrosis and cyst formation. There was Kupffer cell hyperplasia, central vein congestion and portal triads were infiltrated with lymphocytes and plasma cells. Liver parenchyma was infiltrated with lymphocyte, giving hepatitis like picture. It can be concluded that Lithium carbonate on long term treatment in rats causes hepatic degeneration, hepatitis and necrosis. So, it is advised that patients on lithium therapy should be periodically evaluated for hepatic dysfunction.
\end{abstract}

Key words: Lithium carbonate, microanatomy, liver, Albino rats.

\section{Introduction}

Lithium (Greek, meaning Stone) was discovered by Arfwedson in $1811^{[1]}$. Lithium carbonate $\left(\mathrm{Li}_{2} \mathrm{CO}_{3}\right)$, salt form of lithium, is commonly used as a psychiatric medication for the treatment of mania, both acutely and in the long term. ${ }^{[2,3]}$ The therapeutic uses of lithium also include as an augmenting agent in depression, schizoaffective disorder, aggression, impulse control disorder, eating disorders, attention deficit disorder and in certain subsets of alcoholism. Lithium has been used in many medical disorders, especially cluster headache and dermatological disorders (seborrheic dermatitis, eczematoid dermatitis, and genital herpes). ${ }^{[4]}$ Initially, lithium was used to treat Urinary calculi and gout with little success ${ }^{[5]}$, till Cade, J. (1949) ${ }^{[6]}$ reported its antimanic effect. Lithium belongs to alkali group of metals, having atomic no.3 and atomic weight of 6.93. It is water soluble, non protein bound and is distributed in all body fluids. ${ }^{[7]}$ Lithium is readily absorbed after oral administration and its peak level is reached in 2-4 hrs. About $95 \%$ of absorbed lithium carbonate is excreted in urine; about $1 \%$ in feces and $4-5 \%$ in sweat. ${ }^{[8,2]}$ Lithium binds poorly to high and low molecular weight plasma proteins but binds strongly to very low molecular weight legands. ${ }^{[9]}$ As it moves slowly from extracellular compartment to intracellular space, it may require 6-8 days to reach steady blood concentration and desired therapeutic responses. ${ }^{[2]}$

Distribution of lithium in the human organs is almost uniform; it is concentrated in tissues like brain, kidney, thyroid, bone, liver, and muscle cells against concentration gradient. ${ }^{[2]}$ Lithium becomes widely distributed in the central nervous system and interacts with a number of neurotransmitters, decreasing norepinephrine release and increasing serotonin synthesis. It has been reported that lithium can alter the glucose metabolic set point ${ }^{[10]}$ and inhibits the phosphoglucomutase. ${ }^{[1]}$ An increase in fructose 2, 6- biphophate levels had been observed with lithium treatment but it does not affect the cytochrome P-450. ${ }^{[12]}$

1.1 Aim of the study: Lithium carbonate is widely used to treat maniac depressive psychosis. As the therapy is prolonged one, it is unlikely to be without undesirous side effects on various organs including the highly metabolic organ, the liver. The present study is aimed to analyze the histological changes that occur in liver on prolonged use of Lithium in Albino rats and try to correlate these findings to human beings.

\section{Material and Methods}

After institutional Animal Ethics Committee approval, 60 Albino Rats (average weight $150 \mathrm{gm}$ ) were housed under uniform husbandry conditions. The rats were divided in two groups: Group A (control group) of 15 rats were fed with routine diet and water ad. Libitum, Group B: this group of 45 rats was fed with routine diet, water and pellets of flour mixed with lithium carbonate. The animals of two groups were kept in different cages labeled (A) and (B). 
Dose of the drug: - Dose of the drug was calculated by converting adult human therapeutic dose $(600-2400 \mathrm{mg}$ /day) to animal dose. ${ }^{[7,13]}$ The average dose of lithium carbonate amounted to $30 \mathrm{mg} / \mathrm{kg}$ of weight of rats per day.

To study the effects of the drug, five rats from group (A) i.e. control group and 15 rats from group (B) i.e. drug treated group were sacrificed at intervals of four, eight and twelve weeks. The animals were anesthetized with chloroform, a midline incision was given on the anterior abdominal wall, muscles retracted, liver excised, and preserved in $10 \%$ formalin. The tissues were processed by standard histological technique; $5 \mu \mathrm{m}$ thick sections were prepared, stained with Haematoxylin and Eosin stain, observed under compound light microscope and observations recorded.

\section{Observations}

Control group Animals of control group remained healthy and active throughout the experiment. No pathological changes were noticed on gross or microscopic examination of liver and heart of animals of control group.

Drug treated group On gross examination, it was observed that surface of liver was smooth and soft in control group, but in drug treated animals the consistency was firm. The liver showed change in color from reddish brown in control group to greyish in drug treated group. Some of the drug treated animals showed 1-2 cysts in their liver. (Fig.1)

Histological examination of liver (table no. 1) revealed intact capsule in all the animals. Microscopic changes were evident after eight weeks of drug treatment. The drug treated animals showed hepatic degenerations like indistinct cell outlines, loss of normal architecture of hepatocytes and nuclear degeneration at 8 weeks of drug treatment. As the duration of exposure to drug increased, the hepatic degeneration finally led to necrosis in $20 \%$ of animals (fig.2). The hepatic cords were distorted; the sinusoids dilated. Portal tracts were infiltrated with lymphocytes, plasma cells and kupffer cells, known as portal-triaditis. Portal triaditis occurred in $20 \%$ animals at 4 weeks, which increased to $40 \%$ at 8 weeks and $60 \%$ at 12 weeks. Lymphocytic infiltration was also observed in hepatic parenchyma which was not breaking the limiting plate and gave the appearance of chronic persistent hepatitis in latter stages of drug treatment. Bile duct proliferation was noticed in portal areas. The central veins were dilated and congested. There was sinusoidal congestion at 8 weeks of drug treatment which resulted in sinusoidal hemorrhages in $20 \%$ of animals at 12 weeks. (fig. 3 )

Table No. 1: Microscopic findings of liver at 4,8 and 12 weeks of lithium treatment

\begin{tabular}{|l|l|l|l|}
\hline Findings & $\mathbf{4}^{\mathrm{TH}}$ week $(\mathbf{n}=\mathbf{1 5} ; \mathbf{\%})$ & $\mathbf{8}^{\mathrm{TH}}$ week $(\mathbf{n}=\mathbf{1 5} ; \mathbf{\%})$ & $\mathbf{1 2}^{\mathrm{Th}}$ week $(\mathbf{n}=\mathbf{1 5} ; \mathbf{\%})$ \\
\hline Capsule & Intact & Intact & Intact \\
\hline Architecture & Preserved & Deranged + & Deranged ++ \\
\hline Cyst formation & Absent & Present $(\mathrm{n}=3 ; 20 \%)$ & Present $(\mathrm{n}=6 ; 40 \%)$ \\
\hline Central vein congestion & Absent & Present + & Present ++ \\
\hline Portal triaditis & Present $(\mathrm{n}=3 ; 20 \%)$ & Present $(\mathrm{n}=6 ; 40 \%)$ & Present $(\mathrm{n}=9 ; 60 \%)$ \\
\hline Hepatitis & Absent & Present $(\mathrm{n}=3 ; 20 \%)$ & Present $(\mathrm{n}=9 ; 60 \%)$ \\
\hline Necrosis & Absent & Absent & Present $(\mathrm{n}=3 ; 20 \%)$ \\
\hline Sinusoidal hemorrhages & Absent & Absent & Present $(\mathrm{n}=3 ; 20 \%)$ \\
\hline Fatty change & Absent & Absent & Present $(\mathrm{n}=3 ; 20 \%)$ \\
\hline Lymphocytic infiltrations & Present + & Present ++ & Present +++ \\
\hline Pleomorphism & Absent & Present + & Present ++ \\
\hline
\end{tabular}

\section{Discussion}

Since lithium carbonate is highly effective in controlling and preventing recurring manic depressive episodes, its use in psychiatry to rehabilitate patients continues despite its complications. ${ }^{[14]}$ Structural and functional effects of lithium carbonate have been studied by various workers from time to time, ${ }^{[15-17]}$ but effects of lithium carbonate on the microanatomy of liver have not received much attention.

In the present study, on gross examination, a gradual decrease in weight of liver was noticed as the duration of drug treatment increased. The surface of the liver was firm and colour changed from reddish brown to greyish. In addition, white spots on the surface of liver were noticed, which inside were corresponding to cysts.

Microscopically, the hepatocytes showed indistinct cell outline, some of them showed marked cytoplasmic and nuclear degeneration with loss of normal architecture. Focal areas of necrosis were followed by cyst formation. The Sinusoidal spaces increased and there was Kupffer cell hyperplasia. There was also periportal lymphoplasmacytic infiltration known as portal triaditis. The central veins were congested and there were hemorrhages in the sinusoids. Similar changes were observed by Shah et al. ${ }^{[8]}$ On section of the cyst, the cyst wall consisted of degenerative hepatocytes and the cavity of the cyst contained hemorrhagic fluid.

Sharief et al ${ }^{[7]}$ studied the adverse effect of withdrawal of chronic lithium therapy on livers of rabbits and found cholangitis, central veins congested and lymphocytic infiltration of the liver parenchyma, supporting the 
findings of the present study. They did not report any derangement of the hepatic architecture, but in the present study there was cytoplasmic and nuclear degeneration, followed by necrosis and cyst formation. They also reported development of cholangiocarcinoma in the rabbits after 4 weeks of lithium therapy, no such development was observed in the present study, may be because in the present study we used therapeutic dose of lithium carbonate, whereas Sharief et al ${ }^{[7]}$ used double the therapeutic dose in their study.

The hepatotoxicity of lithium carbonate has been explained on the basis of two independent mechanisms:

1. Biotransformation of the drug in the liver with the formation of toxic metabolites.

2. Induction of an allergic hypersensitivity reaction. ${ }^{[19]}$

The former mechanism seems to be working in this experimental study rather than the other one as no allergic infiltrate like eosinophils was observed in liver parenchyma. Similar hepatic changes in laboratory animals could also be observed by dose dependent effect of directly acting therapeutic agents. Both inflammatory and congestive changes had also been reported in liver of lithium treated animals. ${ }^{[20]}$

\section{Conclusion}

From the above discussion it can be concluded that liver undergoes structural derangement with prolonged treatment with Lithium Carbonate. Main effects on liver are:-

- Indistinct cell outline

- Cytoplasmic and nuclear derangement

- Focal areas of necrosis with cyst formation

- Increase in space of sinusoids with hyperplasia of Kupffer Cells lining the sinusoids.

- Periportal lymphoplasmacytic cell infiltration.

- Congestion and Dilatation of central veins.

Acknowledgements

We are thankful to Dr. Mansoor Ahmad Laharwal, Assistant professor, Department of Pathology, Government Medical College Srinagar, J \& K, India, for interpreting the histopathology of slides and helping in tacking Microphotographs

\section{References}

[1]. Schou M, Amidsen A, Jonsen SE, Olsin T. Occurrence of goiter during treatment with Lithium. BMJ 1968; 3: 710-713

[2]. Groleau, G. Lithium toxicity. Emerg Med Clin N Am 1994; 12: 511-531.

[3]. Sharma SD, Iqbal M. Lithium induced toxicity in rats: a haematological, biochemical and histopathological study. Biol Pharm Bull 2005; $28: 834-837$.

[4]. Jefferson JW, Griest JH. Lithium. In: Kaplan and Sadock's Comprehensive textbook of psychiatry, 8th ed. Sadock BJ, Sadock VA, editors. Lippincott William and Wilkins: Phildelphia; p. 2839-51.

[5]. Marmol F. Lithium: bipolar disorder and neurodegenerative diseases. Possible cellular mechanisms of the therapeutic effects of lithium. Progress in Neuro psychopharmacology and Biological Psychiatry 2008; 32(8): 1761-1771

[6]. Cade JFJ. Lithium Salts in the treatment of Psychotic Excitement. Australian Med Journal 1949; 36:349-52

[7]. Sharif N, Rabia A, Iftikhar O. Adverse effects of withdrawal of chronic lithium therapy on liver - a histological study. Pakistan J Zool 2011 ; 43(6): 1155-80.

[8]. Steven, Lippmann. Is Lithium Bad for Kidney? J Clin Psychiatry 1982; 43:220-223.

[9]. Clarke WB, Clarke RM, Olson EK, Barr RD and Downing RG. Binding of lithium and boron to human plasma proteins. Biol. Trace Element Res 1998; 65: 237-249.

[10]. Grier GW, Davis LC and Pfeifer WD. Effects of lithium on inducible enzymes of rat liver. Hor. Met. Res. 1996; 8: $379-383$.

[11]. Csutora P, Karsal A, Nagy T, Vas B, Kovacs G, Rideg O, Bogner P and Miseta A. Lithium induces phosphoglucomutase activity in various tissues of rats and in bipolar patients. Int J Neuropsychpharmacol 2005; 1: 1-7.

[12]. Daniel W and Netter KJ. Alteration of cytochrome P- 450 by prolonged administration of imipramine and/or lithium to rats. NaunynSchmiedebergs. Arch Pharmacol 1990; 342:234-240.

[13]. Toghiani T, Gholami M, Zendedel A, Assadollahi V. The Effects of Low-Dose Lithium Carbonate on the Spermatogenic Parameter in the adults Male Wistar Rats. Life Sci J 2012;9(4):4360-4367].

[14]. Nciri R, Allagui MS, Vincent C, Murat JC, Croute F and El-Felki A. The effects of sub chronic lithium administration in male Wister mice on some biochemical parameters. Hum. Exp. Toxicol. 2009, 28: 641-646.

[15]. Barry Gerson S. Side effects associated with Lithium Therapy. Arch. Gen. Psychiatry, 1779, 36: 879-887

[16]. Hansen Hc. Renal Toxicity of Lithium. Drugs, 1981, 22: 461-476.

[17]. Possey RE, Lithium carbonate dermatitis. JAMA, 1972, 221:1517.

[18]. Shah MS, Hassan G. Effects of Lithium on histology of kidney, liver, Spleen and Skin of Rat.JK Practitioner, 1995, 2: 174-175.

[19]. Kumar V, Abbas AK, Fausto N. In: Pathologic basis of disease (eds. CE Alpers, DC Anthony, JC Aster, JM Crawford, CP Crum and UDGirolami), 7th edition. Elsevier Saunders. Philadelphia, Pennsylvania, 1999.

[20]. Loghin F, OlinicA,Popa DS, Socaciu C, Leucuta SE. Effects of long-term administration of lithium and hydrochlorothiazide in rats. Met Based Drugs, 1995, 6: 87-93. 


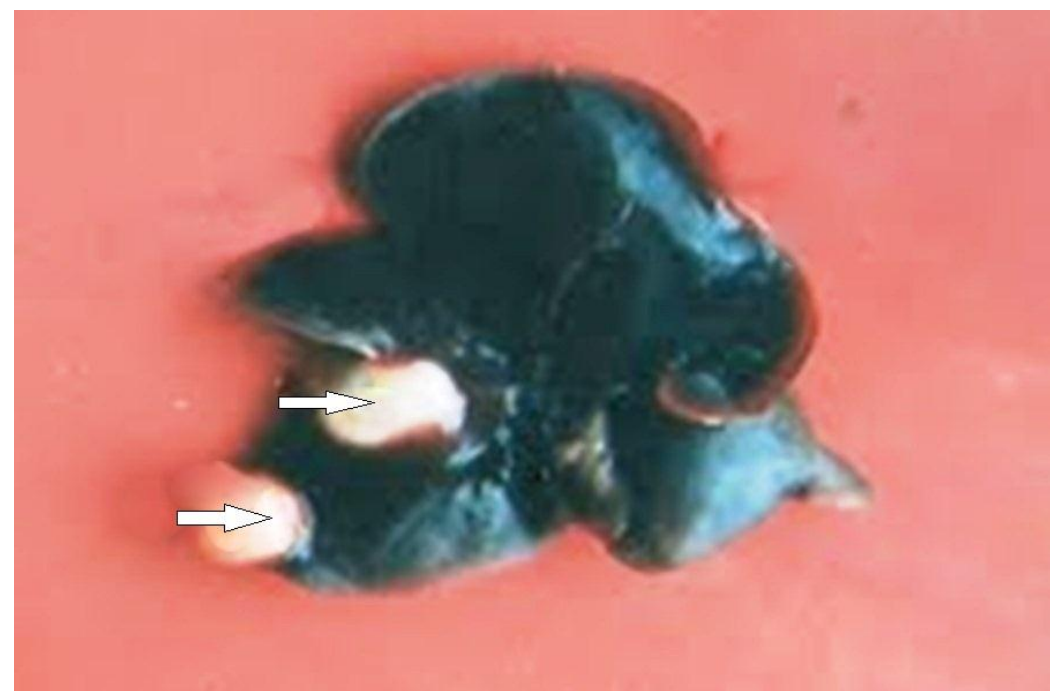

Fig. 1 Photograph of liver of Albino rat after eight weeks of drug treatment showing gross Features and cyst formation (Arrows).

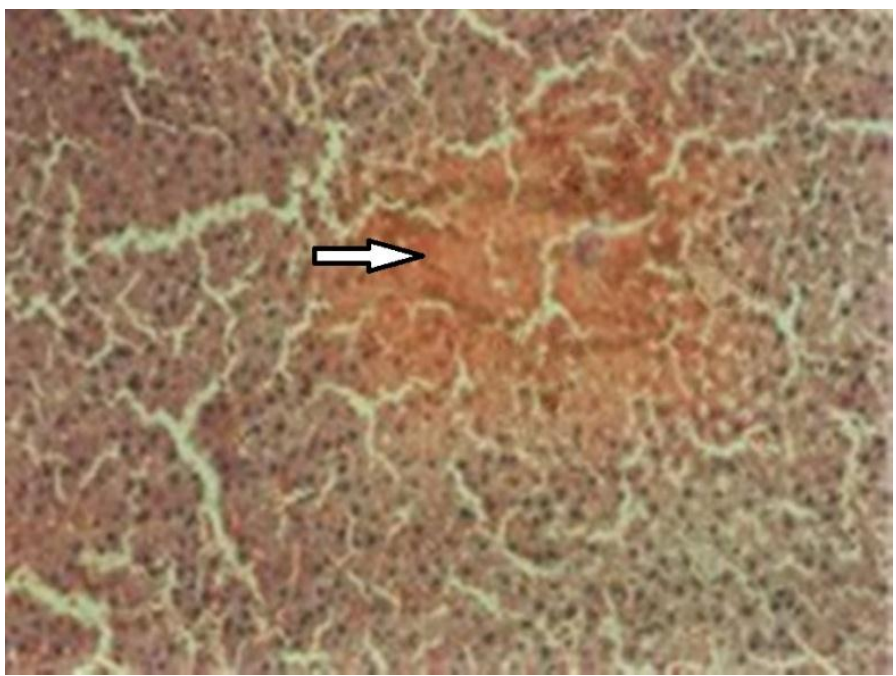

Fig. 2 Microphotograph of liver showing degeneration and necrosis (arrow) after 12 weeks of drug treatment $(\mathrm{H} \& \mathrm{E} \times 100)$

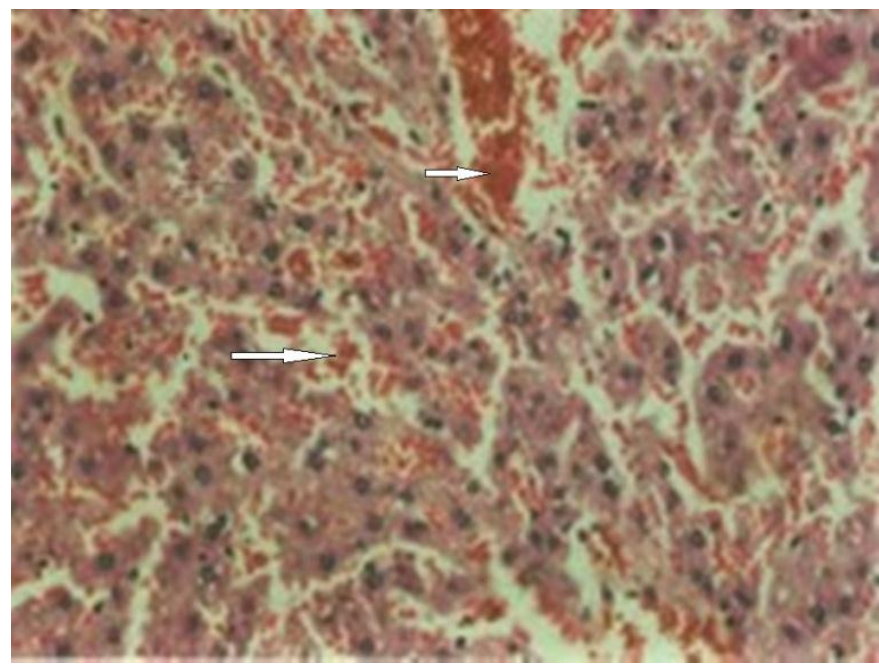

Fig.2 Microphotograph of liver showing hemorrhages in dilated sinusoids (arrows) after 12 Weeks of drug treatment (H\&Ex100). 